\title{
Produção de significados na atividade de formação do pibid/uniso de língua inglesa
}

\author{
Daniela Aparecida Vendramini Zanella1 \\ Maria Angélica Lauretti Carneiro2
}

\begin{abstract}
Resumo: O grupo do Pibid de Língua Inglesa da Universidade de Sorocaba (Uniso) atuou por um semestre elaborando unidades didáticas de ensino-aprendizagem de língua inglesa e desenvolvendo-as com os alunos na escola pública. O objetivo deste texto é registrar a experiência dos educadores no projeto e constatar se o grupo produz significados acerca do Pibid e quais seriam eles. O estudo está fundamentado na teoria da atividade sócio-históricocultural (VYGOTSKY e colaboradores, 2001) e em questões de linguagem na perspectiva dialógica (BAKHTIN/VOLOCHINOV, 2010). A análise é desenvolvida com base em excertos advindos das experiências dos educadores e embasada pelo aporte teórico-metodológico da pesquisa crítico-colaborativa (MAGALHÃES, 2009). Os excertos são discutidos tendo como norte algumas categorias que centralizam os aspectos enunciativo-discursivos e linguísticos (LIBERALI, 2013), sendo interpretados mediante a contribuição teórica apresentada neste trabalho. Ao lidar com as experiências dos educadores, a discussão constata dificuldades, ansiedades e desejos de atuar em sala de aula como significados produzidos sobre o Pibid de Língua Inglesa na Uniso.
\end{abstract}

Palavras-chave: Formação docente. Língua inglesa. Pibid. Produção de significados.

\section{The production of meaning in the pibid/uniso activities of english language education}

\begin{abstract}
The English Language Pibid group at University of Sorocaba (Uniso) worked for a semester preparing English teaching didactic proposals and developing them with students of a public school. This text aims at describing the English Language Pibid educators' experience in the project and verifying if the group produces meanings about Pibid and what these would be. The study is theoretically based on the social-historical-cultural activity theory (VYGOTSKY and collaborators, 2001), and in the dialogic perspective of language
\end{abstract}

\footnotetext{
${ }^{1}$ Mestre em Educação pela Universidade de Sorocaba (2003) e doutora em Linguística Aplicada e Estudos da Linguagem pela Pontifícia Universidade Católica de São Paulo (2013). Atualmente é professora titular do curso de Letras Português e Inglês da Uniso e leciona disciplinas de ensino-aprendizagem de língua inglesa e literatura estrangeira. Coordena o grupo "Tempo de Aprender" (Uniso) que visa à formação crítico-criativa de professores de língua inglesa e o PIBID Capes da Uniso, subárea: inglês. É integrante do grupo de pesquisa LACE - Linguagem e Atividade em Contexto Escolar.

2 Mestre e Doutora em Linguística Aplicada pela Universidade Estadual de Campinas e Universidade de Sorocaba. Graduada em Letras pela Universidade de Sorocaba, Coordenadora geral do Pibid /Capes/Uniso.
} 
(BAKHTIN/VOLOCHINOV, 2010). The analysis is developed from excerpts of the educators' experience, theoretically and methodologically grounded in Critical-Collaboration Research (MAGALHÃES, 2009). The excerpts are discussed from categories that focus on enunciativediscursive and linguistic aspects (LIBERALI, 2013) and interpreted under the theoretical base presented in this work. The analysis shows difficulty, anxiety and desire to act in teaching education as the English Language Pibid production at Uniso.

Keywords: Teacher education. English language. Pibid. Meaning production.

\section{INTRODUÇÃO}

O Programa Institucional de Bolsa de Iniciação à Docência (Pibid), de iniciativa da Capes, objetiva antecipar o vínculo entre futuros educadores e as salas de aula da rede pública. Nas licenciaturas da Universidade de Sorocaba (Uniso), o Pibid vem sendo desenvolvido e ampliado desde 2012. Com bolsas concedidas por esse órgão de fomento federal, os estudantes têm a oportunidade de vivenciar a prática docente na escola pública e seus desafios. $\mathrm{O}$ Pibid tem se mostrado o lócus institucionalizado de prática social que potencializa as possibilidades existentes na estrutura educacional atual. É de se notar também o seu papel na ampliação de formas de recriação de novos padrões sociais e no fortalecimento de uma cultura colaborativa na formação de educadores.

No ano de 2014, o subprojeto Língua Inglesa do Pibid iniciou suas atividades sob a orientação da coordenadora deste subprojeto. Os educadores reuniram-se quinzenalmente na Uniso, elaboraram unidades didáticas, discutiram sobre ensino-aprendizagem de língua inglesa e acompanharam semanalmente as aulas desta disciplina, ministradas por uma professora supervisora numa escola pública da rede estadual da modalidade ensino integral. Durante este acompanhamento, além de observar e auxiliar a professora supervisora, os educadores puderam atuar na sala de aula, desenvolvendo com os alunos as unidades didáticas elaboradas nas reuniões de formação. 
O objetivo central da atividade de formação dentro do Pibid de Língua Inglesa era promover o diálogo entre teoria e prática no que se referisse a conceitos de ensino-aprendizagem. Ou seja, orientar o educador para estabelecer esse diálogo, possibilitando que se tornasse autônomo e elaborador de suas aulas, evitando-se, assim, que viesse a exercer sua profissão guiado por práticas reprodutivas. Por isso, o grande interesse em acompanhar esse momento da prática pedagógica, transformando-o numa "rede viva de troca, criação e transformação de significados de modo a unir fazeres e saberes" (PEREZ GOMES, 2001, p. 85). Nesse contexto, sublinha-se a possibilidade de vivenciar a sala de aula e desenvolver as unidades didáticas com os alunos da rede pública tendo como ponto de partida o contexto da escola em que o Pibid atua. Para isso, foram elaboradas quatro unidades didáticas de ensinoaprendizagem de língua inglesa, e, ao final do semestre, os educadores descreveram a realização da experiência do Pibid de Língua Inglesa.

Apesar de as unidades didáticas serem aqui comentadas, o foco nesta discussão é direcionado às experiências dos educadores. Ao final do semestre, esses bolsistas foram questionados sobre os ganhos e as dificuldades geradas pelo Pibid de Língua Inglesa, e suas respostas foram gravadas e transcritas. $\mathrm{Na}$ análise dos excertos selecionados, verificam-se suas experiências com o Programa num contexto de elaboração e discussão do tópico ensinoaprendizagem de língua inglesa, tendo em vista a integração entre escola pública e a universidade. Nessas experiências, os bolsistas identificam, sobretudo, as aproximações e os distanciamentos entre a produção do conhecimento teórico e a prática cotidiana docente.

Do ponto de vista do Pibid de Língua Inglesa, ambas devem estar articuladas de modo a se redefinirem mutuamente, sem que se caia, de um lado, "em um praticismo em que a teoria ocupa lugar secundário, ou nenhum, na construção e na análise da prática, ou, de outro, em um foco excessivo na 
transmissão da teoria isolada da prática" (MAGALHÃES, 2004, p. 62). Nos trabalhos de Kleiman (2001) e Magalhães (2004), as discussões teóricas sobre a formação de educadores levam em conta tanto a existência de uma não diretividade na relação teoria e prática, quanto o fato de que, conforme Carneiro (2005), os modos de falar dos alunos de graduação não correspondem àqueles que são legitimados pelas instituições.

O grupo Pibid de Língua Inglesa produz significados na medida em que trabalha com a formação docente. De acordo com os pressupostos teóricos que embasam esta discussão, a teoria da atividade sócio-histórico-cultural (TASHC), de Vygotsky e colaboradores (2001), a formação docente é uma atividade, sendo motivada por um objeto e produtora de significados. Coloca em relevo o ser humano como aquele que constitui as relações sociais estabelecidas no contato dialético com o mundo que o cerca e se constitui nessas relações. Neste estudo, a formação docente é entendida como uma atividade em que os educadores produzem significados sobre suas experiências no Pibid de Língua Inglesa, conforme será explicado a seguir.

\section{A ATIVIDADE DE FORMAÇÃO DOCENTE NA TASHC E A PRODUÇÃO DE SIGNIFICADOS SOBRE O PIBID}

A TASHC foi desenvolvida primordialmente por Vygotsky (1934) e, posteriormente, estudada e expandida por seus seguidores, como Leontiev (1977), Davydov (2008), Newman e Holzman (2002) e Engeström (1999, 2009). O ponto de partida para o entendimento desta teoria está enraizado na filosofia marxista, já que a TASHC concebe a atividade de trabalho como condição essencial da existência humana e transformadora do próprio sujeito e da sociedade (NETTO, 2009).

A perspectiva marxista da TASHC enfatiza a busca por contextos reais de pesquisa, analisando a atividade, em seu processo, numa dada investigação, 
como algo capaz de transformar os contextos envolvidos através dos processos de intervenção vividos pelos pesquisadores e demais participantes. No estudo em questão, a escola pública, lócus da atividade de formação docente do Pibid, torna-se o contexto real de pesquisa, dentro do qual se torna possível sua própria transformação, bem como a da universidade, outro contexto envolvido no processo. Esta mudança é o resultado dos processos experimentados pelos educadores, bolsistas do Pibid, professores supervisores, coordenadores de área e, ainda, alunos da escola de Educação Fundamental II. Pressupõe a compreensão e a reabilitação da universidade e da escola como espaços culturais, sociais e políticos "onde é possível salientar a relatividade de todas as formas de significações"' (CARNEIRO, 2005).

A estrutura de um sistema de atividade humana, para Engeström (1999), pode ser representada pelo triângulo vygotskiano que relaciona o sujeito com o objeto mediado por artefatos culturais. Nesse sistema humano, aponta Liberali (2009), os sujeitos que desejam um objeto atuam, dentro de uma comunidade, mediante regras e a divisão de trabalho, de forma não isolada, pois as atividades estão conectadas umas às outras, constituindo redes de sistemas de atividade (ENGESTÖM, 1999).

Neste texto, o conceito de atividade a define como algo motivado por um objeto e capaz de produzir significados. Ainda dentro desse conceito, considerase que cada participante possui seu papel e se engaja (ou não) em participar da atividade compartilhando um resultado. Nessa direção, a formação docente é compreendida como uma atividade em que os sujeitos produzem sentidos e significados sobre suas futuras práticas como educadores na escola pública, tendo a oportunidade de partilhar entre si estas experiências.

Em outras palavras, o Pibid, como uma dimensão de formação, constitui um espaço de produção de novos conhecimentos e intercâmbio de saberes, com o objetivo de pensar e repensar a prática de todos os envolvidos no projeto. A 
perspectiva dialógica de linguagem insiste nesta interação entre participantes como central para a necessidade de escuta de uma multiplicidade de vozes, para a adesão do outro e a retomada de algo já dito que torne possível sua ressignificação. Ou seja, nessa visão, a língua é compreendida em uma perspectiva histórica que "não se transmite: dura e perdura sob a forma de um processo evolutivo e contínuo" (BAKHTIN/VOLOCHINOV, 2010, p. 111). Assim sendo, o partilhamento e a construção dos conhecimentos só serão possíveis se sustentados por uma atividade interacional que promova o encontro de diferentes perspectivas, no interior de um "posicionamento dialógico em que os significados possam ser rearticulados e reconstruídos" (CARNEIRO, 1995).

$\mathrm{Na}$ visão de formação docente ligada à TASHC, é possível discutir a perspectiva dialógica de linguagem, na qual os significados são produzidos pelo embate de sentidos existente na relação pensamento e linguagem, cerne para a compreensão da natureza da atividade e da consciência humana (LIBERALI, 2011). Neste estudo, as experiências dos educadores podem ou não implicar uma produção de significados sobre o Pibid de Língua Inglesa.

Para Vygotsky (2004), sentido e significado formam uma unidade inseparável da vida sócio-histórico-cultural do sujeito. O autor analisa os conceitos de sentido e significado no pensamento verbal e no discurso interno. $\mathrm{Na}$ tentativa de explicar que a linguagem transforma a estrutura e o funcionamento da consciência, ele destaca o significado e o define como a unidade de análise da relação entre pensamento e linguagem, atividade e consciência. Ainda nessa perspectiva, o significado é utilizado para discutir os aspectos da generalização socialmente estabelecidos por uma palavra e pode ser considerado uma produção social de natureza relativamente estável: o significado "é a estrutura da operação do signo, é o que se encontra entre o 
pensamento e a palavra" (VYGOTSKY, 2004, p. 179). Logo, para o teórico, conhecer o significado é "conhecer o singular como universal" (p. 186).

O sentido, por sua vez, é descrito por Vygotsky, nesta relação entre consciência e atividade, como a "soma de todos os eventos psicológicos que a palavra desperta na consciência" (VYGOTSKY, 2001, p. 181). Ou seja, o sistema de relações e inter-relações das palavras que se constituem no confronto entre significações estabelecidas e vivência pessoal.

\section{PROCEDIMENTOS METODOLÓGICOS}

Este artigo discute o projeto Pibid de Língua Inglesa, caracterizado como pesquisa crítica de colaboração, na qual se investigam as próprias práticas na atividade de formação docente. Segundo Magalhães (2009, p. 65), este paradigma "tem como objetivo intervir e transformar contextos, de modo a propiciar que os participantes aprendam por meio da participação coletiva na condução da pesquisa".

Nesta opção teórico-metodológica, é esperado que os educadores percebam suas transformações atuando em conjunto com a coordenadora do subprojeto e com a supervisora. Os diversos sistemas de atividades são utilizados para questionamentos e produções colaborativas referentes aos objetivos propostos e às necessidades dos contextos específicos (MAGALHÃES, 2009, p. 63). No caso deste estudo, tais sistemas se compõem do projeto Pibid de Língua Inglesa (que liga teoria e prática nos encontros de formação docente na universidade) e das aulas de língua inglesa na escola pública (em que se colocam em prática questões relativas à elaboração de unidades didáticas). Nesses encontros de formação docente, realiza-se a negociação de significados em produção de conhecimento. 


\subsection{Descrição do contexto.}

Os encontros ocorridos na universidade são parte da atividade de formação docente. A atividade de formação apresentam como objeto a elaboração de unidades didáticas de ensino-aprendizagem de língua inglesa, com base nas experiências particulares de ação. Essas unidades didáticas são desenvolvidas pelos educadores em uma escola pública estadual de uma cidade do interior paulista, graças à parceria articulada pelo Pibid. A escola faz parte do modelo de Ensino Integral, implantado pela Secretaria de Educação do Estado de São Paulo por meio da Lei Complementar n⿳o 1.164, de 4 de janeiro de 2012.

O modelo prevê uma jornada de oito horas e meia no Ensino Fundamental e de nove horas e meia no Ensino Médio, incluindo uma estrutura que conta com salas temáticas nas áreas do conhecimento e professores que atuam em regime pleno de dedicação (cf. Resolução SE no 84, de 19 de dezembro de 2013, da SEE-SP).

No modelo de Ensino Integral, focaliza-se o trabalho de formação de “jovens autônomos, competentes e solidários", conforme estabelecido pela SEE (2012, p. 15), que, desta forma, promove o denominado "protagonismo juvenil". Entre outras vantagens, o protagonismo juvenil possibilita ao aluno tornar-se o ator principal das ações, atuando como sujeito nas atividades de ensinoaprendizagem, para, assim, adquirir uma postura crítica de quem age e realiza seus objetivos.

Ao lado deste protagonismo, considerado um dos princípios educativos que sustentam o modelo de Ensino Integral, criou-se também o chamado "projeto de vida", que deve ser o ponto de intersecção das ações e metodologias destinadas a apoiar o estudante na construção deste modelo de ensino (SEE, 2012, p. 14). 
Conforme mencionado, o objetivo da atividade de formação do Pibid de Língua Inglesa foi manter o diálogo entre teoria e prática no tocante aos conceitos de ensino-aprendizagem. Dessa forma, o Programa possibilita vivenciar a sala de aula mediante o desenvolvimento de unidades didáticas de ensino-aprendizagem de língua inglesa com os alunos da rede pública, tendo como ponto de partida o contexto do Ensino Integral em que ele atua. As unidades didáticas elaboradas pelos educadores apresentam a tentativa de interligar os tópicos dos cadernos do Estado indicados pela SEE com o protagonismo juvenil e o projeto de vida. Estas elaborações são embasadas pela Proposta Curricular de São Paulo (SEE, 2008) e pelo ensino-aprendizagem por meio de atividade social.

A noção de ensino-aprendizagem por meio de atividade social é formulada por Liberali (2009), que, partindo da discussão de consagrados autores sobre diferentes áreas de conhecimento - como linguagem, psicologia, filosofia e pedagogia -, propõe uma elaboração de organização curricular fundada numa perspectiva de ensino-aprendizagem sócio-histórico-cultural (VYGOTSKY, 2001, 2004). Essa perspectiva diferencia-se das outras por considerar os envolvidos como sujeitos engajados na produção de conhecimento (VENDRAMINI ZANELLA, 2013). Isto é, na atividade de formação docente do Pibid de Língua Inglesa, os educadores, a professora supervisora e a coordenadora buscam a formação docente não como simples receptores, mas como sujeitos.

\subsection{Os procedimentos de coleta e análise de dados}

Os excertos aqui estudados advêm de experiências no Pibid de Língua inglesa relatadas pelos educadores em um encontro de formação na Universidade de Sorocaba. Neste encontro ocorrido em três de junho de 2014, 
estavam presentes os dez educadores/bolsistas e a coordenadora do subprojeto Língua Inglesa.

Com a intencionalidade de instaurar um embate argumentativo, a coordenadora elaborou uma pergunta controversa, na medida em que cria possibilidade de respostas com perspectivas diversas e permite aos interlocutores assumir posicionamentos (LIBERALI, 2013, p. 68). As experiências relatadas pelos educadores originaram-se desta questão controversa, que interroga sobre os ganhos e as dificuldades em atuar como bolsista do Pibid de Língua Inglesa.

Para a análise dos excertos, foram focalizados aspectos enunciativodiscursivos e linguísticos, com base em pressupostos de Liberali (2013). Nas questões enunciativas, discutiram-se o local e o momento de produção, recepção e circulação das experiências, bem como o papel social dos interlocutores na produção dessas.

Em relação às questões discursivas, analisaram-se a organização e a articulação do texto oral relativo às experiências e buscou-se constatar se houve ou não desenvolvimento e se o enunciado foi ou não pertinente à questão controversa, resultando nas dimensões: desenvolvimento e pertinência (PONTECORVO, 2005, p. 69; VENDRAMINI ZANELLA; LIBERALI, 2011). O

desenvolvimento consiste em "avançar e progredir, coletivamente, a análise, bem como a interpretação e a definição do objeto de discurso, mediante a introdução de novos elementos e de novas perspectivas" (PONTECORVO, 2005, p. 69). O não desenvolvimento é a situação de inércia da sequência, quando há o bloqueio do raciocínio do grupo. Em relação à dimensão pertinência, esta permite verificar se o tópico proposto foi seguido ou se se desviou dele, comprometendo a progressão (ou não) do discurso.

Finalmente, quanto às questões linguísticas, investigam-se as escolhas lexicais e os operadores argumentativos, conceitos encontrados nos trabalhos de 
Koch (2010) e Liberali (2013). O objetivo deste exame é constatar se os educadores produzem significados sobre o Pibid de Língua Inglesa.

$\mathrm{Na}$ análise dos excertos, os nomes dos nove educadores que aparecem nos recortes e o nome da professora supervisora são substituídos por suas iniciais (A., C., Cl., D., Ell., E., F., P. e S.).

\subsection{A produção de significados sobre o Pibid de Língua Inglesa.}

Como mencionado, apresentam-se nos excertos as experiências dos educadores expostas por meio da questão controversa elaborada pela coordenadora do subprojeto. Normalmente, os encontros são conduzidos pela coordenadora, que faz a abertura, a introdução, o alinhamento do tópico e o seu fechamento. Vejamos: Coordenadora: “Como foi o semestre como bolsista Pibid de Língua Inglesa? Que dificuldades e ganhos você obteve na formação de professor (interligando teoria e prática)? O que ainda ocasiona dificuldades, ansiedades e inseguranças?".

Partindo da questão controversa, os educadores inserem seus comentários, organizados de forma que todos participem e exponham seus pontos de vista na discussão. Entretanto, muitas vezes, ocorre de alguém retomar o turno ou inserir comentários fora da sequência, mas o desenvolvimento do tópico permanece sob a condução da coordenadora. Inicialmente, constata-se, nos dados transcritos, que os educadores temem a possibilidade de cometer um erro em seus pontos de vista:

CL: Acho que dificuldades, por incrível que pareça, acho que porque estou com uma série que me identifico mais por ser mais velho, eu não tô tendo nenhuma. E, assim, da parte que acrescenta, tô tendo que ser mais paciente, eu queria que as pessoas produzissem rápido e cada um tem seu tempo lá. Então, você tem que aprender que cada um tem seu andar. 
Além disso, já falei aqui uma vez e vou repetir, que eu fiquei tão integrada lá, me dediquei tanto um dia que fui voltar para casa e errei o ônibus. Me dei tanto de mim lá, que a hora que saí de lá, desligou. Mas é isso, para eu ter mais paciência.

A insegurança e o medo de errar ficam evidentes nas escolhas lexicais: "acho", que modaliza a opinião, "por incrível que pareça" e "nenhuma". Apesar de essas palavras e expressões, separadamente, poderem estar ligadas a uma postura de segurança, nesse excerto, ao serem utilizadas juntas, materializam certa dificuldade em atuar. Koch (2010, p. 30-40) oferece-nos esta percepção ao categorizar operadores argumentativos entre os quais figuram os encontrados no excerto: “assim (responsável por introduzir no enunciado conteúdos pressupostos); além disso (soma argumentos a favor de uma mesma conclusão); mas (contrapõe argumentos orientados para conclusão contrária e demarca a intenção de adicionar)".

A utilização desses operadores permite conectar ideias por meio de diferentes formas de vinculações que geram aprofundamentos do tópico em discussão (LIBERALI, 2013). Com essa articulação, Cl. desenvolve o tópico de forma pertinente ao apresentar seu ponto de vista relacionado ao questionamento feito pela coordenadora, inserindo elementos novos (ser mais paciente, ficar integrada à escola, dedicar-se e errar o ônibus), e mantendo-os ligados ao tópico inicial: ganhos, ansiedades e inseguranças.

Em algumas experiências, como as dos educadores Ell., C. e P., destacase a insegurança em relação à fluência na língua inglesa. No excerto abaixo, essa insegurança é materializada no discurso pelo uso das expressões "fica meio perdida" e "coisa que você não lembra", "ou não sabe":

Ell: Às vezes, por não ter a fluência em inglês, eles perguntam alguma coisa e eu fico "como é mesmo?". Aí você fica meio perdida na hora.

C.: Quanto à fluência, às vezes, eles perguntam e "não, mas como que é? vamos pesquisar" e, às vezes, você acaba 
pesquisando junto com o aluno e acaba aprendendo até junto com ele alguma coisa que você não lembra, ou não sabe.

P.: Outra dificuldade é a fluência, mas a gente vai se apoiando na R. C., [risos], a gente vai se ajudando".

Retomando a afirmação de Vygotsky (2004) sobre a unidade formada pelos sentidos e significados, indissociável da vida sócio-histórico-cultural do sujeito na atividade, compreende-se que os sentidos expressos pelos educadores constituem significados sobre a necessidade de aprimorar o conhecimento da língua inglesa para atuar na escola de EFII.

Também se constata que, ao retomar o tópico em seus turnos, os educadores, C. e P., trazem elementos novos relacionados ao trabalho conjunto: C.: "aprendendo até junto"; P.: "mas (operador argumentativo que contrapõe argumentos orientados para conclusões contrárias) a gente vai se apoiando na R. C., a gente vai se ajudando".

Essa ação coletiva é realizada no Pibid de Língua Inglesa no momento em que os educadores compreendem-se como sujeitos engajados na atividade em que compartilham, mesmo que parcialmente, o mesmo objetivo. Nesse caso, o objeto - assumir papel de educador e atuar no ensino-aprendizagem de língua inglesa na escola pública - permite que as dificuldades sejam amenizadas. Isso implica a produção do seguinte significado do Pibid de Língua Inglesa: mesmo enfrentando dificuldades, a atividade nesse programa é realizada em conjunto, de forma colaborativa, e, atuando dessa maneira, os educadores percebem suas transformações (MAGALHÃES, 2009).

Os educadores discorreram também sobre questões do modelo do Ensino Integral:

Ell: Gostei muito da experiência de descobrir o modelo de escola integral. Diferente de outras escolas estaduais. Achei muito interessante. 
C: Apesar de não conseguir tanto inserir o inglês nas eletivas, esse projeto vai vir a calhar, pois eles vão ter um diálogo próprio e irão levar tudo o que aprenderam durante o semestre para esse projeto, mostrar para os pais.

Nesse excerto, aparecem algumas evidências de que os educadores reconhecem questões do novo modelo que estão vivenciando. É o caso da frase "Diferente de outras escolas estaduais", da escolha lexical "eletivas" (uma estratégia para a ampliação do universo cultural do aluno, segundo preconizado pela SEE) e da expressão "diálogo próprio", que se interliga ao protagonismo juvenil e que é um dos princípios educativos do modelo de escola integral. O educador C. utiliza o operador argumentativo "apesar de", que traduz argumentos orientados para uma conclusão contrária, a de que as aulas eletivas não são produtivas. Utiliza ainda o operador argumentativo "pois", que introduz uma explicação relativa ao enunciado anterior: "esse projeto vai vir a calhar." Com base nessas sustentações, constata-se que o tópico inicial, apresentando elementos novos - ensino integral e disciplinas eletivas continuou a desenvolver-se com pertinência.

Os conhecimentos sobre o modelo de ensino integral e sobre protagonismo juvenil e projeto de vida são pontos de vista no discurso que constituem mais um significado do Pibid de Língua Inglesa: a importância de unir fazeres e saberes, ambos essenciais na atividade de formação docente.

Na sequência, F. insere seu ponto de vista introduzindo um elemento novo - aulas na escola pública e na escola particular - por meio do qual ele dá continuidade ao desenvolvimento do tópico inicial, desta vez, abordando os ganhos e dificuldades na atuação no Pibid:

F: Para mim foi uma mudança total sobre o pensamento de dar aulas no ensino público, porque, até então, eu já tinha dado aula na escola particular e, quando me perguntavam se eu daria aula na escola pública, eu dizia: "não, nunca que eu daria aula na escola pública!". Com o Pibid lá na escola, eu passei a 
adorar... eu gosto de estar lá, eu quero. Agora eu penso de fato em dar aula no ensino público. Foi uma quebra total dos meus pensamentos em relação ao ensino. Quanto às dificuldades, impor realmente uma disciplina durante a aula, né? Quando você está conversando com eles, você está tentando ensinar, é diferente do ensino particular em que eu dou aula. Lá, você dá uma bronca, eles ficam quietos, lá estão pagando também, agora, lá é complicado essa parte aí.

Nesse excerto, F. inicia seu discurso comentando sua mudança de opinião e sustenta seu ponto de vista com o operador argumentativo "porque", que introduz uma explicação sobre o enunciado anterior. Essa mudança de F. é observável também pelas escolhas lexicais, "nunca", "adorar", "gosto" e "quero", que expressam os sentidos relativos a antes de atuar na escola pública e mostram os novos sentidos sendo produzidos após a experiência no Pibid.

Apesar de F. revelar alguns sentidos em desenvolvimento acerca do ensino público, ainda apresenta marcas relacionadas aos privilégios da escola particular:

“é diferente do ensino particular em que eu dou aula. Lá, você dá uma bronca, eles ficam quietos, lá estão pagando também, agora, lá é complicado essa parte aí". Esses sentidos de F., se compartilhados com outros, podem culminar no significado Pibid de Língua Inglesa de que a escola pública é mais restritiva cultural e socialmente.

Introduzindo, na sequência, um elemento novo - método da professora supervisora, S. -, os educadores E., C. e D. inserem seus pontos de vista no desenvolvimento do tópico inicial:

E: Para mim foi uma experiência nova, nunca tinha trabalhado em uma escola pública, em nenhuma outra escola. Acho que foi uma experiência fácil, pois a gente só acompanha a professora supervisora. A gente não tem que se impor, não tem que tomar alguma decisão lá. Isso fica para a S., isso é a parte boa do Pibid. Uma coisa em que prestei atenção e que aconteceu nessa segunda foi que a S. nunca tinha participado na aula de cup 
song com a gente, isso a gente fazia sozinhos, e, nessa última aula, foi bem difícil porque tinha três alunos que não estavam conseguindo acompanhar [...], e eu comecei a explicar só para eles, para que todos conseguissem fazer juntos. Mas as meninas que estavam lá e já sabiam toda a sequência começaram a falar: "ah, seu burro, você não sabe e tá atrapalhando a gente". E eu não sabia o que responder, não sabia muito como lidar. Aí, a S. chegou e conseguiu contornar a situação, ela falou para os alunos que eles tinham que aprender [...]. Ensinou com eles cantando a música, que era em inglês. A maioria conseguiu então acompanhar. [...] Então, a aula tomou outro rumo, e eu parei para pensar no método que a $S$. usou para chegar onde ela chegou.

C. : [...] eles estavam atrapalhando muito a aula. Aí, a S. colocou eles para fora, bem brava, mas foi lá fora conversar com eles. Aí, eles voltam assim supertranquilos, se sentam e ela também, volta supertranquila. Aí eu falei para ela: “da próxima vez que isso acontecer, eu vou com você lá fora para ver o que você fala com eles" [risos]. E todos adicionam: "O que ela fala, né?".

D. : Aí fiquei observando o comportamento dela e me imaginando no lugar dela. Fico pensando: "poxa! será que eu vou conseguir ter essa firmeza?"

Em alguns momentos, para elaborar seu ponto de vista, E. desvia o tópico, o que poderia comprometer a progressão do discurso gerando a não pertinência. Entretanto, ao final de seu turno, utiliza o operador argumentativo "então", que introduz argumentos alternativos, e estes conduzem a conclusões diferentes ou opostas.

Nesse excerto, alguns sentidos carregam a ideia de que existe um método usado pela professora supervisora, uma fórmula para lidar com situação conflituosa na sala de aula. Tais sentidos são materializados linguisticamente em: “[...] pensar no método que a S. usou para chegar onde ela chegou”; "mas (operador argumentativo que exprime argumentos orientados para conclusões contrárias) foi lá fora conversar com eles. Aí, eles voltam assim supertranquilos, se sentam e ela também, volta supertranquila"; "o que ela fala, né?"; “observando o comportamento dela e me imaginando no lugar dela. Fico pensando: "poxa! será que eu vou conseguir ter essa firmeza?". 
Mesmo imbuídos da ideia de que há um método, os educadores desse grupo produzem o seguinte significado Pibid de Língua Inglesa: com o tempo, S. adquiriu experiência e, por isso, consegue unir fazeres e saberes, possibilitando o que Pérez Gómez (2001, p. 85) conceitua como uma "rede viva de troca, criação e transformação de significados". Da perspectiva da TASHC, esse significado é facultado pelos sentidos compartilhados, advindos das falas dos educadores acerca do papel social de S., a professora supervisora do Pibid de Língua Inglesa, e também acerca de seus próprios papéis sociais (ainda demonstram a impossibilidade de atuar como a S.).

Ainda em relação à questão do papel social de educador do Pibid, observa-se a dificuldade de A. em enfrentar uma turma que colocava em pauta seu papel como tal:

A.: A dificuldade que encontrei foi deles não me enxergarem como professora em formação no começo e a sexualidade deles, mas não sabia lidar. Mas, para que isso parasse, bastou a S. me dar a voz em sala de aula. Ela pediu para eu explicar o projeto que eu queria fazer. Na outra aula, logo em seguida, eles começaram a me tratar muito diferente, porque daí eles conseguiram me enxergar como professora. Essa foi uma dificuldade porque eu não esperava, sabe, [...] eu conseguia enxergar outros milhares de problemas, mas nunca me enxergar uma [...], uma sexy appel. Sei lá, uma sexy symbol para eles. Não consegui imaginar. Teve dias que eu fiquei muito mal, pensando: "ai, será que a culpa é minha?" Sei lá, se eu estava me portando errado, eu não sabia se era eu ou eles o problema. Mas aí a S. me deu a palavra, nem sei se foi de propósito, só sei que ela disse: "ah, eu vou passar a palavra para você explicar seu projeto".

O problema enfrentado por A. é visível em suas escolhas lexicais: "não me enxergarem", "sexualidade", "me portando errado" e "eu não sabia". Em contrapartida à situação descrita, ela insere comentários sobre como S. a auxiliou para que promovesse seu papel social de educadora. Para isso, A. utiliza operadores argumentativos, como o "mas": "mas, [...] bastou a S. me dar 
a voz em sala de aula"; "mas aí a S. me deu a palavra, nem sei se foi de propósito, só sei que ela disse: ‘ah, eu vou passar a palavra para você explicar seu projeto' ".

À luz da TASHC, em que significados são produzidos pelo embate de sentidos na relação existente entre pensamento e linguagem (LIBERALI, 2011), a expressão "me dar a voz" também sugere a produção de um significado Pibid de Língua Inglesa. Trata-se da chance de ouvir e ser ouvido na atividade de formação docente. Isso coloca em relevo a importância da multiplicidade de vozes e da adesão do outro no processo de ressignificação dos diferentes papéis na atividade, o que somente é possível quando se adotam novas práticas discursivas no interior das matrizes interacionais, para, assim, se estabelecerem formas mais igualitárias de participação (CARNEIRO, 1995).

\section{CONSIDERAÇÕES}

Este artigo registrou a experiência do subprojeto Pibid de Língua Inglesa, na Uniso, situado no contexto de atividade de formação de educadores. $O$ subprojeto incluiu a elaboração de unidades didáticas de ensino-aprendizagem de língua inglesa, que foram desenvolvidas com os alunos de uma escola pública. O objetivo do texto centrou-se em registrar a experiência dos educadores no projeto e constatar se o grupo produzira significados acerca do Pibid de Língua Inglesa e quais teriam sido eles.

Conforme já comentado, as unidades didáticas criadas apresentam a tentativa de interligar os tópicos dos cadernos do Estado com o princípio do protagonismo juvenil e com o projeto de vida. Foram elaboradas com base na Proposta Curricular de São Paulo (SEE, 2008) e na organização curricular de ensino-aprendizagem por meio de atividade social (LIBERALI, 2009; VENDRAMINI ZANELLA, 2013). 
Apesar de as unidades didáticas terem sido comentadas neste estudo, o foco da discussão é direcionado às experiências dos educadores no Pibid de Língua Inglesa, sobretudo, aos seus ganhos e dificuldades nessa atuação.

Os excertos analisados no artigo foram selecionados dessas experiências, sendo transcritos e trabalhados dentro de uma perspectiva que focaliza os aspectos enunciativo-discursivos e linguísticos, proposta por Liberali (2013).

Para interpretar e discutir os dados, e identificar a produção de significados acerca do Pibid de Língua Inglesa, fundamentou-se teóricometodologicamente em Vygotsky (1934), Bakhtin/Volochinov (2010) e na Pesquisa Crítica de Colaboração (MAGALHÃES, 2009, 2011).

Entre as principais questões apontadas pelos dados, constataram-se três categorias de interpretação na produção de significados sobre o Pibid: dificuldade com a fluência, dificuldade e ansiedade diante da ideia de assumir o papel de educador e desejo de atuar em sala de aula. Dos significados produzidos pelo grupo sobre suas experiências no Pibid de Língua Inglesa, destacaram-se:

- Mesmo com as dificuldades, a atividade do Pibid foi realizada em conjunto, de forma colaborativa (educadores, coordenadora e professora supervisora), conforme propõe Magalhães (2009), e, ao atuar em conjunto, os educadores perceberam suas transformações.

- Os educadores apropriaram-se de saberes como o modelo de ensino integral, o protagonismo juvenil e o projeto de vida (SEE, 2012). Inicialmente, experimentaram unir fazeres e saberes, algo essencial na formação docente, na medida em que supõe trocas e transformação de significados.

- Há um método de condução da aula e manutenção da disciplina dos alunos que somente S., a professora supervisora do Pibid de Língua Inglesa, conhece.

- Os educadores ainda demonstram papéis sociais marcados pela dificuldade em atuar como a professora supervisora. 
- A professora supervisora constitui-se com o papel social de uma professora experiente em função de seu tempo de atuação, e, por isso, consegue unir saberes e fazeres.

Por fim, a produção de significados do Pibid de Língua Inglesa, analisada sob a perspectiva da TASHC, pressupôs educadores engajados na participação em uma atividade da qual compartilharam os resultados: assumir o papel de educador e atuar no ensino-aprendizagem de língua inglesa na escola pública. Os educadores permitiram a exposição de sentidos advindos daquilo que vivenciaram e de que se apropriaram.

\section{REFERÊNCIAS}

BAKHTIN, M. M. (VOLOCHINOV, V. N.). Marxismo e filosofia da linguagem: problemas fundamentais do método sociológico na ciência da linguagem [1929]. Tradução Michel Lahud e Yara Frateschi Vieira. 14. ed. São Paulo: Hucitec, 2010.

BRASIL. Ministério da Educação. PIBID: Programa Institucional de Bolsa de Iniciação à Docência. Brasília, 2013. Disponível em:

<http://www.capes.gov.br/educacao-basica/capespibid. Acesso em: abr. 2013.

CARNEIRO, M.A. L. A prática de reflexão metadiscursiva: desenvolvimento de leitura do professor em formação. 2005. Tese (Doutorado em Linguística Aplicada) - Instituto de Estudos da Linguagem, Universidade Estadual de Campinas, Campinas, 2005.

CARNEIRO, M.A. L. O papel do professor na construção da prática social da leitura. 1995. Dissertação (Mestrado em Linguística Aplicada) - Instituto de Estudos da Linguagem, Universidade Estadual de Campinas, Campinas, 1995.

DAVYDOV. V. V. The basic concepts of contemporary psychology. In:

Problems of developmental instruction: a theoretical and experimental psychological study [1986]. New York: Nova Science Publishers, 2008.

ENGESTRÖM, Y. Learning by expanding: an activity-theoretical approach to developmental research. Helsinki: Orienta-Konsultit, 1999. 
ENGESTRÖM, Y. The future of activity theory: a rough draft. In: SANNINO, A. et al. (Org.). Learning and expanding with activity theory. Nova York: Cambridge University Press, 2009.

FREIRE, P. Pedagogia do oprimido [1970]. 17. ed. Rio de Janeiro: Paz e Terra, 1987.

KLEIMAN, A. B. A formação do professor: perspectivas da linguística aplicada. Campinas: Mercado de Letras, 2001.

KOCH, I. G. V. A inter-ação pela linguagem. 10. ed. São Paulo: Contexto, 2010.

LEONTIEV, A. N. Activity, consciousness and personality [1977]. Englewood Cliffs, NJ: Prentice Hall, 2003.

LIBERALI, F. C. Argumentação em contexto escolar. Campinas, SP, 2013.

LIBERALI, F. C. Atividade social nas aulas de língua estrangeira. São Paulo: Moderna, v. 1., 2009.

LIBERALI, F. C. Cadeia criativa: uma possibilidade para a formação crítica na perspectiva da teoria da atividade sócio-histórico-cultural. In: MAGALHÃES, M. C. C.; FIDALGO, S. S. (Org.). Questões de método e de linguagem na formação docente. Campinas, SP: Mercado de Letras, 2011. p. 41-64.

LIBERALI, F. C. Formação de alunas-professoras de línguas: rumos para uma sociedade crítica e sustentável. In: GIMENEZ, T.; MONTEIRO, M. C. (Org.). Formação de professores de línguas na América Latina e transformação social. Campinas: Pontes, 2010. p. 71-92. (Coleção Novas Perspectivas em Linguística Aplicada, v. 10).

LIBERALI, F. C. Gestão escolar na perspectiva da teoria da atividade sóciohistórico-cultural. In: LIBERALI, F.; MATEUS, E.; DAMIANOVIC, M. C. (Org.). A teoria da atividade sócio-histórico-cultural e a escola: recriando realidades sociais. Campinas: Pontes, 2012. p. 89-108.

MAGALHÃES, M. C. C. (Org.). A formação do professor como profissional crítico: linguagem e reflexão. Campinas, SP: Mercado de Letras, 2004. p. 59-85. (Coleção As faces da linguística aplicada).

MAGALHÃES, M. C. C. O método para Vygotsky: a Zona de Desenvolvimento Proximal como zona de colaboração e criticidade criativas. In: SCHETTINI, R. 
H. et al. (Org.). Vygotsky: uma revisita no início do século XXI. São Paulo: Andross, 2009. p. 53-78.

MAGALHÃES, M. C. C. Pesquisa crítica de colaboração: escolhas epistemometodológicas na organização e condução de pesquisa de intervenção no contexto escolar. In: MAGALHÃES, M. C. C.; FIDALGO, S. S. (Org.). Questões de método e de linguagem na formação docente. Campinas, SP: Mercado de Letras, 2011. p. 13- 39.

NEWMAN, F; HOLZMAN, L. Lev Vygotsky: cientista revolucionário. [1993]. Tradução de Marcos Bagno. São Paulo: Loyola, 2002.

NETTO, J. P. O que é marxismo. 2. ed. São Paulo: Brasiliense, 2009. (Coleção Primeiros Passos, 148).

PÉREZ GÓMEZ, A. A cultura escolar na sociedade neoliberal. Tradução Ernani Rosa. Porto Alegre: Artmed, 2001.

PONTECORVO, C. Discutir, argumentar e pensar na escola: o adulto como regulador da aprendizagem. In: PONTECORVO, C; AJELLO, A. M.; ZUCCHERMAGLIO, C. (Org.). Discutindo se aprende: interação social, conhecimento e escola. Porto Alegre: Artmed, 2005.

SÃO PAULO (Estado). Secretaria da Educação Estadual (SEE). Proposta Curricular de São Paulo, 2008.

SÃO PAULO (Estado) Secretaria da Educação Estadual (SEE). Diretrizes do Programa de Ensino Integral, 2012. Disponível em: <http://www.educacao.sp.gov.br/a2sitebox/arquivos/documentos/342.pdf $>$.

Acesso em: 13 jun. 2014.

VENDRAMINI ZANELLA, D. A. Por uma formação crítico-criativa de alunasprofessoras e professora-pesquisadora na graduação em Letras. 2013. Tese (Doutorado em Linguística Aplicada e Estudos da Linguagem) - Pontifícia Universidade Católica de São Paulo, São Paulo, 2013.

VENDRAMINI ZANELLA, D. A.; LIBERALI, F. C. Brincar no hospital: uma produção criativa na formação de alunos-educadores. Linguagem $\mathcal{E}$ Ensino, Pelotas, v. 14, n. 1, p. 93- 113, jan./jul. 2011.

VYGOTSKY, L. S. A construção do pensamento e da linguagem [1934]. São Paulo: Martins Fontes, 2001. 
Revista Letras Raras

ISSN: 2317-2347 - Vol. 7, Ano 4, N0 2 - 2015

VYGOTSKY, L. S. Teoria e método em psicologia [1934]. 3. ed. São Paulo: Martins Fontes, 2004.

Recebido: em 26 de agosto de 2015

Aceito: em 24 de outubro de 2015 